\title{
AS FEIRAS DE CIÊNCIAS DA UFG/RC: CONSTRUINDO CONHECIMENTO
}

\author{
Simara Maria Tavares Nunes \\ Fernanda Welter Adams ${ }^{* *}$ \\ Scarlet Dandara Borges Alves ${ }^{* *}$ \\ Dayane Graciele dos Santos ${ }^{* * *}$
}

RESUMO: As Feiras de Ciências da Universidade Federal de Goiás/Regional Catalão (UFG/RC) são eventos de grande relevância, repercutindo de maneira significativa em todo o conjunto de escolas e colégios públicos e privados do município de Catalão e Região. O objetivo primordial deste evento é o de despertar e estimular o interesse de alunos de Ensino Médio, Profissional ou Tecnológico, Fundamental e Educação Infantil de escolas das redes pública e privada pelas Ciências (em geral, em todas as áreas do Conhecimento). Aliás, os grandes diferenciais desta Feira de Ciências são a abrangência de todos os níveis de escolaridade, oportunizando inclusive aos alunos da Educação Infantil e Ensino Fundamental 1 a oportunidade de vivenciar a pesquisa e divulgar seus resultados ao público e a abrangência de área de conhecimento. Outros importantes objetivos são estreitar as relações Universidade-Escola, o que tem sido bem sucedido e permitir que as escolas mostrem na Feira de Ciências os seus projetos em andamento, de forma a valorizar os trabalhos que as escolas já realizam, divulgando-os durante o evento, de modo a dar visibilidade aos trabalhos cotidianos de professores e alunos dentro das escolas. Os estudantes são responsáveis pela execução e apresentação dos trabalhos durante o período de realização da Feira de Ciências. No dia da exposição dos trabalhos, cada um deles é avaliado por uma comissão composta por professores da Universidade, egressos dos programas de pós-graduação da Unidade e professores da Educação Básica com título de Mestre; a avaliação obedece a critérios previamente divulgados como criatividade e inovação; relevância do trabalho; aspecto interdisciplinar; clareza e objetividade na apresentação do trabalho, dentre outros. Tem-se trabalhado desde sempre com a interdisciplinaridade e com o propósito de se agregar todas as áreas do conhecimento. Dentre os resultados alcançados pelas atividades das Feiras de Ciências da UFG/RC, tem - se

\footnotetext{
* Doutora em Ciências pela Universidade de São Paulo (USP). Docente do curso de licenciatura em Educação do Campo da Universidade Federal de Goiás (UFG) - Campus de Catalão. Foi coordenadora de área do PIBID (2009-2014).

* Licenciada em Química pela Universidade Federal de Goiás (UFG) - Campus de Catalão. Desenvolveu pesquisa na área de Ensino de Química, com ênfase em Jogos Didáticos. Especialização em metodologias do Ensino da Química pela AVM Faculdade Integrada.

*** Licenciada em Química pela Universidade Federal de Goiás (UFG). Atualmente é professora da rede estadual - Colégio Estadual Dom Emanuel.

**** Mestre em Química pela Universidade Federal de Goiás (UFG) - Campus Catalão. Atua como professora de Química da rede estadual de ensino.
} 
a participação efetiva da comunidade no evento; professores estimulados a desenvolver atividades de enriquecimento curricular; alunos motivados apresentando um número significativo de projetos para a Feira de Ciências; alunos com desenvoltura para a execução e apresentação de trabalhos científicos e/ou culturais.

Palavras-chave: Feiras de Ciências; Formação cidadã; Metodologia diferenciada de ensino.

ABSTRACT: The Science Fairs of Federal University of Goiás / Regional Catalão (UFG / RC) are highly relevant events impacting significantly on the entire set of public and private schools in Catalão and Region. The primary objective of this event is to arouse and stimulate the interest of high school, Technology, Fundamental Education and Early Childhood students of public and private schools for Science (all knowledge areas). By the way, the great advantages of this Science Fair is the scope of all levels of education, providing opportunities to Early Childhood and fundamental education students to experience research and disseminate their results to the public, beyond the scope of knowledge area. Other important objectives are to strengthen the University-School relations, which have been successful and allow schools to show in the Science Fair its ongoing projects in order to value the work that schools already perform, publicizing them during the event in order to give visibility to the daily work of teachers and students. Students are responsible for implementing and the presentation of the work in the Science Fair. In the exhibition day of the works, each one of them is evaluated by a committee composed for University teachers, Post-Graduation Egresses of the Unit and Basic Education teachers with master's degree; the evaluation is based on criteria previously published as creativity and innovation; relevance of the work; interdisciplinary aspect; clarity and objectivity in the presentation of the work, among others. It has been working always with interdisciplinary approach and with the purpose to aggregate all knowledge areas. Among the results achieved by the activities of the Science Fairs of UFG / RC, has the effective participation of the community in the event; Teachers encouraged to develop activities for curriculum enrichment; motivated students presenting a significant number of projects in the Science Fair; Students with ease for the execution and presentation of scientific and /or cultural work.

Keywords: Feira de Ciências; Citizenship; Differentiated methodology of teaching.

\section{INTRODUÇÃO}

A sociedade contemporânea passa por rápidas transformações tecnológicas e sociais que também repercutem na escola. Assim, exige-se do professor e do processo de ensino-aprendizagem a formação de um cidadão crítico e reflexivo. 
Portanto, devido às rápidas transformações do mundo globalizado, não se deve exigir mais do educando a memorização de conteúdos facilmente superados e sim que este aprenda a aprender. Segundo os PCNs (BRASIL, 1999):

A formação do aluno deve ter como alvo principal a aquisição de conhecimentos básicos, a preparação científica e a capacidade de utilizar as diferentes tecnologias relativas às áreas de atuação. Propõe-se, no nível do Ensino Médio, a formação geral, em oposição à formação específica; o desenvolvimento de capacidades de pesquisar, buscar informações, analisá-las e selecioná-las; a capacidade de aprender, criar, formular, ao invés do simples exercício de memorização.

Após a publicação da Nova Lei de Diretrizes e Bases da Educação Nacional (LDB) (BRASIL, 1996) o conhecimento passa a ter novas abordagens dentro do ambiente escolar. Tem-se hoje como objetivo a formação de cidadãos mais conscientes e que tenham uma visão mais ampla de mundo. Para isso, os professores têm lançado mão de novas metodologias de ensino-aprendizagem, que garantam um ensino significativo e contextualizado com a vida do aluno.

Uma ótima metodologia a ser utilizada são as Feiras de Ciências. As Feiras de Ciências surgiram na década de 1960. Caracterizavam-se por apresentarem trabalhos resultantes de experiências feitas em sala de aula ou montagem de aparelhos com fins demonstrativos (MANCUSO, 1995). Assim, estavam voltadas para a construção de um conhecimento técnico.

Hoje se acredita que as Feiras de Ciências devem ir além da construção de um conhecimento técnico. Acredita-se que as mesmas tenham a capacidade de fazer com que os alunos, por meio de seus próprios trabalhos, envolvam-se em uma investigação científica, nas várias áreas do conhecimento, proporcionando um conjunto de experiências interdisciplinares, tendo a capacidade de complementar o ensino formal.

Por definição de Pereira (2000):

[...] as feiras de ciências ocorrem em locais públicos onde os alunos, após uma atividade de investigação científica, expõem e discutem suas descobertas e resultados, podendo também colocá-lo à disposição da comunidade. Isso possibilita aos alunos expositores 
oportunidades de crescimento científico, cultural e social [...] A realização de Feiras de Ciências é perfeitamente justificada ao considerar-se: os objetivos do Ensino de Ciências; desenvolvimento do pensamento lógico; vivência do método científico (PEREIRA, 2000. p. 20).

Segundo Lima (2004): "As Feiras de Ciências (ou Feiras de Conhecimento ou Feiras de Ciência e Cultura) se apresentam então como um convite para abrir todas as janelas da curiosidade e interesse dos alunos, da criatividade e da mobilização do professor, da vida e sentido social da escola."

Pavão (2004) afirma que do ponto de vista metodológico, as Feiras de Ciências podem propiciar o estímulo para aprofundar estudos e a busca de novos conhecimentos, além de ter a capacidade de proporcionar a discussão de problemas sociais. De acordo com Borba (1996) após a participação em uma Feira de Ciências, o educando adquire uma maior capacidade de decisão em relação aos problemas do cotidiano, pois exercita a capacidade de comunicação.

Dentre os principais objetivos associados às Feiras de Ciências pode-se citar (PEREIRA, 2000) incentivar as atividades científicas, realizando ações interdisciplinares, envolvendo o planejamento e execução de projetos e estimular o aluno na busca e elaboração de conclusões a partir de resultados obtidos por experimentação. Estas ações estimulariam o engajamento intelectual, permitindo ao aluno a elaboração de critérios e sistematização de fatos, proporcionando uma aprendizagem efetiva.

Um levantamento de Mancuso (2000) junto a alunos e professores identificou algumas mudanças positivas nos discentes após sua participação em Feiras de Ciências tais como crescimento pessoal, capacidade de comunicação, estímulo e motivação.

Assim, a realização de Feiras de Ciências é perfeitamente justificada ao se considerar os atuais objetivos do Ensino: desenvolvimento do pensamento lógico; vivência do método científico; universalidade das leis científicas; conhecimento do ambiente e a sondagem de aptidões; a preparação para o trabalho e a integração do indivíduo na sociedade (PEREIRA, 2000). E pode-se acrescentar, ampliação da visão geral sobre o que é ciência e conhecimento científico, já que na atualidade 
prima-se por Feiras de Ciências que não se restrinjam às ciências exatas e ou naturais, mas que leve em consideração também as reflexões científicas das áreas das ciências humanas, das linguagens, das artes e das investigações ambientais e de sustentabilidade, pois todas elas visam ao mesmo propósito de melhorar a vida do homem no planeta.

E essa perspectiva concorda com Barcelos, Jacobucci e Jacobucci (2010) para os quais um dos fatores que contribuíram, nos últimos anos, para uma diversificação das Feiras de Ciências no Brasil, foi a perspectiva de ação interdisciplinar. Para os autores citados, isso significou uma transformação das Feiras de Ciências, pois implicou na necessidade de integração das diferentes disciplinas em um mesmo projeto que pudesse, por seu lado, integrar as áreas do conhecimento na realização de atividades e experimentos. Para Hartmann e Zimmermann (2009) a realização de Feiras balizadas pelo princípio interdisciplinar foi, e pode-se dizer que ainda é, o grande desafio das últimas décadas, para a ampla participação da comunidade escolar nas Feiras de Ciências. Para as autoras acima citadas é preciso ampliar essa integração e relação entre disciplinas, de forma a perceber o sujeito do conhecimento, logo, o ser humano como um todo.

Importante frisar, como o faz Morin (2007), que "o ser humano é a um só tempo físico, biológico, psíquico, cultural, social, histórico" (p. 15), ou seja, a educação não pode prescindir dessas características como base de sua realização. Assim, uma proposta de educação que se vale de uma perspectiva interdisciplinar, ou mais, transdisciplinar, necessita ter como horizonte:

Essa unidade complexa da natureza humana [que é] totalmente desintegrada na educação por meio das disciplinas, tendo-se tornado impossível aprender o que significa ser humano. É preciso restaurála, de modo que cada um, onde quer que se encontre, tome conhecimento e consciência, ao mesmo tempo, de sua identidade complexa e de sua identidade comum a todos os outros seres humanos (MORIN, 2007, p. 15-16).

É, nesse sentido, que na atualidade se propõe o trabalho com Feiras de Ciências. Nesse caso, elas podem ser momento privilegiado de promover a troca e o intercâmbio de experiências múltiplas das várias áreas do conhecimento. Muito mais 
que reproduzir, repetir ou apenas informar sobre as ciências e suas inovações, sejam quais forem, a função dessas Feiras se ampliou, podendo proporcionar a alunos e professores a oportunidade de mostrar suas concepções de mundo, de ciências e de educação.

Neste sentido, as Feiras de Ciências da Universidade Federal de Goiás/Regional Catalão (UFG/RC) objetivam a utilização de uma metodologia diferenciada para a formação de alunos críticos e reflexivos por meio da mostra do que tem sido realizado nas suas salas de aula.

Assim, o objetivo deste trabalho é divulgar as Feiras de Ciência realizadas pela UFG/RC que objetivam, dessa forma, a utilização de uma metodologia diferenciada para a formação de alunos críticos e reflexivos por meio da mostra do que tem sido realizado nas suas salas de aula.

\section{ASPECTO METODOLÓGICO}

Este trabalho, ao buscar divulgar as Feiras de Ciências realizadas pela Universidade Federal de Goiás/Regional Catalão (UFG/RC), traz um breve histórico das quatro edições realizadas e a descrição das perspectivas futuras do evento. Trata-se, portanto, de um relato de experiência, visando propor o trabalho com Feiras de Ciências como um recurso metodológico diferenciado, capaz de promover o processo de ensino e aprendizagem de forma crítica, autônoma e efetiva.

Para se avaliar o impacto das Feiras de Ciências da UFG/RC na formação cidadã dos educandos envolvidos utilizou-se uma pesquisa de caráter quantitativo/qualitativo na última edição do evento e os Resultados são descritos abaixo.

Utilizou-se como instrumento de coleta de dados questionários elaborados com o objetivo de investigar a aceitabilidade da Feira e se esta contribuiu para o processo de ensino/aprendizagem e para a construção de competências e habilidades necessárias para uma formação cidadã.

Para o tratamento dos dados obtidos através dos questionários foi utilizada a Análise Textual Discursiva (MORAES, GALIAZZI, 2007). Este tipo de abordagem 
corresponde a uma análise qualitativa de dados que se inicia com a denominada unitarização dos textos, que os fragmenta em unidades de significado. Ou seja, os dados (informações) foram separados conforme o significado de cada um. Após a unitarização realizou-se o processo de categorização, que consiste em agrupar as unidades de significados semelhantes em categorias. E por último, na etapa de comunicação, foram elaborados metatextos explicitando as concepções surgidas a partir das informações em combinação com os referenciais teóricos, explicitando as percepções que surgiram a partir da análise das respostas obtidas. Ou seja, a análise das informações compuseram textos interpretativos e argumentativos (MORAES, 2003).

Ao final, espera-se incentivar o leitor para a vivência das Feiras de Ciências, tanto enquanto discente, como no papel de professor orientador.

\section{HISTÓRICO DAS FEIRAS DE CIÊNCIAS DA UFG/RC}

As Feiras de Ciências da Universidade Federal de Goiás - Regional Catalão (UFG/RC), têm sido desenvolvidas desde o início no âmbito do Pibid (Programa Institucional de Bolsa de Iniciação a Docência).

A equipe interdisciplinar da Regional Catalão $(R C)$ que integra este projeto tem trabalhado em conjunto desde o ano de 2009, desenvolvendo trabalhos de forma multidisciplinar dentro do Pibid. No início, eram professores e alunos dos Cursos de Química, Biologia, Matemática e Física. Esses subprojetos, como resultado final de projetos temáticos, iniciaram o desenvolvimento de Feiras de Ciências dentro da Escola Parceira em 2009 e 2010.

Em 2011 se uniram a este grupo os professores e alunos dos subprojetos Pibid de História e Geografia e o grupo como um todo continuou a organizar Feiras de Ciências, desta feita em três escolas parceiras e de forma a abranger todas as áreas do conhecimento. Ao final de 2011, o grupo viu a oportunidade de aumentar a abrangência de suas Feiras de Ciências no lançamento do Edital MCTI/CNPq/MEC/CAPES/SEB de apoio à realização de Feiras de Ciências e Mostras Científicas, promovendo agora um evento a nível municipal. 
Quando o grupo iniciou as atividades com Feiras de Ciências as mesmas não aconteciam nas escolas de Catalão há muito tempo. Hoje, quase todas as escolas da cidade realizam suas próprias Feiras de Ciências para selecionar os melhores trabalhos para apresentar na Feira de Ciências da UFG/RC, implicando numa melhora progressiva na qualidade dos trabalhos inscritos na Feira de Ciências da UFG/RC.

\section{1aFeira de Ciências da UFG/RC}

A $1^{\text {a }}$ Feira de Ciências da UFG/RC aconteceu nos dias 29 e 30 de novembro de 2012 e teve como tema "Ciência e Pesquisa na Educação Básica". Este evento teve como objetivo principal despertar e estimular o interesse dos alunos de Ensino Médio e Fundamental 2 de escolas das redes pública e privada de Catalão-GO pela Ciência. Tal iniciativa se consolidou com o apoio dos Bolsistas Pibid dos Cursos de Química, Física, Matemática, Geografia, História e Ciências Biológicas da Universidade Federal de Goiás/Regional Catalão (UFG/RC) que auxiliaram na divulgação da Feira de Ciências em escolas públicas e privadas.

No primeiro dia do evento houve uma palestra voltada para os discentes de licenciatura da Universidade, onde foi apresentado 0 projeto de ensino/aprendizagem baseado num planetário móvel da Universidade de Brasília (UnB). No segundo dia do evento, o Planetário Móvel funcionou durante toda a apresentação dos trabalhos, chamando a atenção dos visitantes.

Durante todo dia 30/11/2015, alunos e professores do Ensino Fundamental 2 e Técnico expuseram em stands montados na quadra coberta do campus os mais diversos trabalhos nas áreas de Ciências da Natureza, Matemática e suas Tecnologias e Ciências Humanas e suas Tecnologias. Experiências que demonstravam fenômenos físicos, projetos de temática ambiental, resgate da memória, maquetes de cidades e até um planetário móvel, trazido por estudantes da Universidade de Brasília (UnB), chamaram a atenção dos visitantes.

Foram premiados os melhores trabalhos de cada nível - Ensino Fundamental Il e Ensino Médio através de patrocínios recebidos de empresas da cidade. Esta 
primeira edição da Feira de Ciências da UFG/RC contou com 50 trabalhos inscritos e aprovados para apresentação no evento. Percebeu-se que muitos trabalhos foram obtidos da internet, porém observaram-se diversos trabalhos criativos como 0 desenvolvimento de um tijolo a base de isopor.

Já na primeira edição do evento se contou com o apoio da Secretaria de Educação e Cultura de Catalão e Subsecretaria de Educação do Estado de Goiás.

\section{2ª Feira de Ciências da UFG/RC}

A $2^{\text {a }}$ Feira de Ciências da UFG/RC ocorreu nos dias 24 e 25 de outubro de 2013. Puderam participar os estudantes regularmente matriculados em instituições de ensino públicos e privados do Ensino Fundamental 1 ( $1^{\text {a }}$ ao $5^{\underline{a}}$ ano) (primeira vez

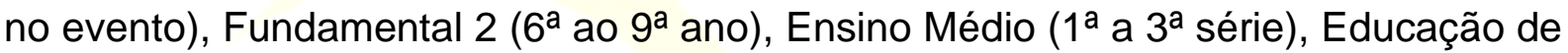
Jovens e Adultos (EJA) (do $6^{\underline{a}}$ ao $9^{\underline{a}}$ ano do ensino fundamental e das séries do Ensino Médio) pertencentes ao município de Catalão e região. Cada grupo deveria ser composto por dois a três integrantes (mínimo e máximo) e um professor orientador do trabalho.

Cada grupo deveria escolher um tema relacionado com uma dessas áreas do conhecimento, porém os alunos foram estimulados a desenvolverem projetos interdisciplinares. A escolha do tema era de inteira responsabilidade dos grupos juntamente com o professor orientador, o que já de início buscava estimular o protagonismo estudantil.

Para a divulgação da $2^{a}$ Feira de Ciências da UFG/RC nas escolas do município desenvolveu-se uma oficina onde se relatou a vida e obra de Leonardo da Vinci, personalidade homenageada do evento. No primeiro dia de Feira (24/10/2013) desenvolveu-se a oficina "Leonardo Da Vinci: Ciência a Flor da Pele", onde se exibiu e discutiu o filme "O Código da Vinci", dirigido por Ron Howard. A oficina era voltada aos alunos do Campus e também aberta aos alunos da Educação Básica, que também compareceram no evento. Após o filme houve discussões sobre a mensagem do mesmo e também sobre a vida e obra de Leonardo da Vinci. 
No segundo dia da Feira (25/10/2013) os grupos formados pelos alunos das redes pública e privada da cidade de Catalão-GO e região apresentaram os seus trabalhos para o seus pares, para os visitantes da Feira de Ciências e também para a Comissão Avaliadora do Evento. Cada trabalho foi avaliado por uma comissão composta por professores da Universidade e da Educação Básica.

Os alunos expositores e o público visitante também elegeram o melhor trabalho da $2^{\text {a }}$ Feira de Ciências da UFG/RC na categoria voto popular.

Os alunos que participaram desta atividade eram em sua maioria (86\%) alunos da rede pública de ensino de escolas pertencentes tanto à sub-secretaria Estadual quanto à Secretaria Municipal de Educação da cidade de Catalão-GO; os demais $(8 \%)$ eram alunos de uma escola particular da mesma cidade. De um total de 132 alunos inscritos, 66\% destes eram do sexo feminino e 34\% do sexo masculino, com faixa etária entre 13 e 20 anos de idade. A $2^{a}$ Feira de Ciências da UFG/RC teve 47 trabalhos inscritos, sendo 42 apresentados, num total de 126 alunos que mostraram seus trabalhos. Nesta edição 15 professores orientadores participaram da Feira de Ciências, que contou com a visitação de mais de 600 pessoas, constituídas por alunos da UFG/RC, comunidade escolar e comunidade em geral.

Do total dos participantes, somente $29 \%$ já haviam participado de Feiras de Ciências anteriormente, ou seja, a maior parte dos alunos (o equivalente a $71 \%$ ) participaram pela primeira vez de uma Feira de Ciências. Assim, a $2^{a}$ Feira de Ciências da UFG/RC foi a primeira oportunidade para muitos de conhecer/vivenciar a elaboração, produção e o desenvolvimento de trabalhos para uma Feira de Ciências.

Durante a realização da $2^{\text {a }}$ Feira de Ciências da UFG/RC os alunos apresentaram trabalhos e para isto precisaram estudar, pesquisar e interpretar dados sobre o assunto do trabalho de forma a primeiramente entender e assim poder explicar aos visitantes da Feira de Ciências; este processo permitiu que os alunos aprendessem a aprender e ainda desenvolvessem diversas competências e habilidades como criar, pois precisaram elaborar um projeto de forma criativa; apreender de forma diferenciada, pois foram chamados a buscar o conhecimento e 
não recebê-lo de forma passiva; a falar em público e se comunicar, pois tiveram que mostrar seus trabalhos aos visitantes e serem cidadãos críticos, pois foram instigados a buscar as aplicações e implicações sociais e ambientais de seus projetos.

A partir desta atividade realizou-se a prática reflexiva e pôde-se avaliar uma série de pontos positivos através do uso desta metodologia, pois há o crescimento e compartilhamento de experiências, tanto para professores, alunos, funcionários, como também para os organizadores.

\section{$3^{\text {ă }}$ Feira de Ciências da UFG/RC}

A 3a Feira de Ciências da UFG/RC ocorreu no dia 07 de novembro 2014. Puderam participar os estudantes regularmente matriculados em instituições de ensino públicos e privados da Educação Infantil (novidade no evento), Ensino Fundamental 1 ( $1^{\mathrm{a}}$ ao $5^{\mathrm{a}}$ ano), Fundamental 2 (6 $6^{\mathrm{a}}$ ao $9^{\mathrm{a}}$ ano), Ensino Médio e Técnico ( $1^{\underline{a}}$ a $3^{\underline{a}}$ série), Educação de Jovens e Adultos (EJA) (do $6^{\underline{a}}$ ao $9^{\underline{a}}$ ano do ensino fundamental e das séries do Ensino Médio) pertencentes ao município de Catalão-GO e região. O evento foi divulgado em todas as escolas públicas e particulares de Catalão e região através de uma oficina para divulgação do Edital e elaboração de projetos.

As Inscrições foram realizadas nas próprias escolas diretamente pela equipe organizadora com os professores das escolas. Assim, os monitores estiveram presentes em todas as escolas realizando as inscrições dos trabalhos.

Os trabalhos inscritos foram selecionados por um comitê composto pelos professores membros da Comissão Organizadora e a Lista de Trabalhos aprovados foi divulgada na página do evento na rede (http//feiraciencias.catalao.ufg.br).

Durante a divulgação houve a entrega à Direção da escola, professores e alunos envolvidos no trabalho do Regimento da $3^{\text {a }}$ Feira de Ciências da UFG/RC, no qual estavam descritas as atividades da Feira, o seu dia de realização e os critérios de avaliação dos trabalhos, além de algumas exigências como pontualidade e presença do professor na apresentação do trabalho. 
Foram incentivados trabalhos que partissem das vivências dos alunos e que problematizassem o conhecimento e o cotidiano local e regional, respeitando-se os níveis e as faixas etárias.

O formato de exposição da $3^{a}$ Feira de Ciências da UFG/RC consistiu na apresentação de trabalhos utilizando-se recursos como maquetes, cartazes, pôsteres, pequenos experimentos didáticos, resultados de trabalhos investigativos, protótipos, dentre outros. Durante a exposição os trabalhos foram avaliados por uma Comissão de Avaliação composta por alunos de pós graduação e professores da UFG/RC.

Antes da premiação aconteceu uma apresentação do grupo de Experimentoteca de Física com o show "Física no palco", realizado por um grupo de alunos do Curso de Física da UFG/RC. A equipe, com um show totalmente interativo, executou experimentos físicos e abordou variados conceitos da Física nestes, contando com a participação dos "cobaias" presentes. E, dessa forma, divertiram e ensinaram a todo o público presente através da Física. Por fim, foi realizada a entrega dos prêmios às equipes com trabalhos vencedores em cada categoria, estando entre os prêmios distribuídos medalhas e jogos educativos confeccionados pelo Curso de Licenciatura em Matemática da UFG/RC.

Após a realização da $3^{\text {a }}$ Feira de Ciências da UFG/RC e a fim de se avaliar o evento, um questionário foi aplicado aos expositores e 67 destes aceitaram participar espontaneamente da pesquisa. Destes, 100\% afirmaram ter gostado de participar da $3^{\text {a }}$ Feira de Ciências da UFG/RC e atribuíram notas entre 7 e 10 ao evento (onde 10 era a nota máxima). Em suas justificativas, destacam-se afirmações como: "Na Feira foram apresentadas muitas ideias que podem nos ajudar futuramente" (E20). "A feira permitiu a interação com diversas disciplinas" (E64). "Troca de experiência com os outros grupos" (E05). "Aquisição de conhecimentos e contato com experimentos inovadores" (E19). "A feira é uma forma diferente de estar em contato com o conhecimento, aprendemos e também ensinamos, é uma atividade diferente" (E62).

Quanto aos pontos positivos da Feira de Ciências da UFG/RC, os estudantes participantes do evento citaram pontos como: a Troca de experiências com os outros 
grupos e com os visitantes; a Interação; a Aquisição de novos conhecimentos; as Amizades; a Variedade de ideias; a Motivação aos estudos; a Organização do Evento; a Criatividade dos trabalhos; a Inovação; a Diversidade de projetos; a Participação de diversos alunos; o Suporte aos expositores; a Apresentação de projetos que abordaram a sustentabilidade como o uso adequado da água; o estimulo a pesquisa e a divulgação do trabalho realizado na escola.

Quando questionados se a Escola onde estudam realizou sua própria Feira de Ciências, 45 expositores responderam que sim. Apenas 22 expositores afirmaram que sua Escola não realizou uma Feira de Ciências interna. Vale destacar que esses 22 alunos que não participaram de Feiras de Ciências em suas escolas estudam em instituições particulares e /ou conveniadas.

\section{4ª Feira de Ciências da UFG/RC}

A 4⿳亠丷厂 Feira de Ciências da Universidade Federal de Goiás/Regional Catalão (UFG/RC): "Ciência, Consciência e Sustentabilidade" aconteceu no dia 06 de novembro de 2015 e teve como personalidade homenageada Osvaldo Cruz, cientista brasileiro de grande reconhecimento nacional e internacional.

Foram 83 trabalhos aprovados para apresentação nesta edição, envolvendo 252 alunos e 42 Professores Orientadores. Participaram do Evento 20 Escolas, destacando-se duas escolas da Zona Rural e duas escolas de cidades vizinhas. As cidades envolvidas foram: Catalão, Três Ranchos, Campo Alegre de Goiás e Goiandira. Destacam-se ainda as escolas Colégio Estadual Gilberto Arruda Falcão que é do distrito de Santo Antônio do Rio Verde e a Escola Municipal Maria Barbara Sucena, ambas escolas da Zonas Rurais de Catalão. Apenas uma escola particular fez parte do evento, destacando-se assim o trabalho das escolas públicas.

A divulgação da 4⿳亠丷a Feira de Ciências da UFG/RC foi realizada nas escolas de Catalão e região, tendo sido o evento divulgado em todas as escolas, de sala em sala. Para tanto, foi entregue um oficio ao diretor e ao coordenador pedagógico das escolas, convidando-os para participarem da $4^{\text {a }}$ Feira de Ciências da UFG/RC. Posteriormente foram expostos cartazes da Feira de Ciências, o Regulamento, a 
Ficha de Inscrição e a Ficha de Avaliação nos murais de divulgação nas dependências das escolas. Novamente, como nos anos anteriores, no primeiro semestre de 2015 visitou-se as escolas de sala em sala para convidar os alunos a se inscreverem e sanar qualquer dúvida dos mesmos quanto ao evento e as inscrições.

No mês que antecedeu as inscrições da 4⿳亠丷a Feira de Ciências da UFG/RC a Comissão Organizadora retornou as escolas e repetiu o mesmo processo de divulgação só que como um lembrete aos alunos e novamente esclarecendo dúvidas e orientando os alunos sobre como deveria ser elaborado o resumo e como os trabalhos seriam avaliados. A Comissão Organizadora também buscou auxiliar os alunos no momento de fazerem as inscrições (Redação do Resumo, contendo Introdução, Objetivos, Metodologias e Resultados Previstos).

Durante o processo percebeu-se que cada escola tem sua própria organização para selecionar os alunos e os trabalhos que serão enviados para a Feira de Ciências da UFG/RC. Muitas escolas organizam uma Feira de Ciências interna para selecionar os alunos com seus projetos. Já outras escolas deixam a participação dos alunos em aberto, não fazendo uma seleção prévia. Após fazer uma visita de sala em sala para avisar das inscrições da Feira de Ciências a Comissão Organizadora forneceu um local dentro das próprias escolas a fim de realizar in loco as inscrições dos alunos interessados.

Novamente antes da premiação aconteceu a apresentação da Experimentoteca de Física com o show "Física no palco". Por fim, foi realizada a entrega dos prêmios às equipes com trabalhos vencedores em cada categoria, estando entre os prêmios distribuídos medalhas e troféus, além de livros publicados por professores da Regional Catalão.

\section{PERSPECTIVAS FUTURAS}

A 5 $5^{\underline{a}}$ Feira de Ciências e Mostra Cultural da Universidade Federal de Goiás/Regional Catalão (UFG/RC) acontecerá em junho de 2016. 
O objetivo desta quinta edição é realizar um evento que permita a apresentação dos trabalhos e pesquisas que ocorrem diariamente em sala de aula, incentivando alunos e professores da Educação Infantil, dos Ensinos Fundamental, Médio e Técnico de Catalão e Região a divulgar suas ações e socializar conhecimentos. Almeja-se possibilitar aos alunos a oportunidade de construir conhecimento de forma interdisciplinar, criativa e contextualizada.

Assim, espera-se que a Feira de Ciências da UFG/RC seja um momento de divulgação das atividades realizadas nas escolas, em sala de aula, e um momento de troca e socialização do conhecimento.

\section{AVALIAÇÃO DO EVENTO E A FORMAÇÃO CIDADÃ DOS ALUNOS}

A fim de se avaliar se os objetivos do evento foram alcançados, foi realizado o tratamento dos dados obtidos através dos questionários aplicados aos participantes da última edição do evento utilizando-se a analise textual discursiva, onde foram criadas as categorias Feiras de Ciência da UFG/RC: Construindo Competências e Habilidades (A); Importância das Feiras de Ciências da UFG/RC na Formação Cidadã (B); Feiras de Ciências: Aproximando Universidade e Escola Básica (C), as quais serão; discutidas a seguir:

Feiras de Ciências da UFG/RC: Construindo Competências e Habilidades:

O desenvolvimento de uma Feira de Ciências traz benefícios tanto para os alunos quanto para os professores envolvidos nas atividades e mudanças positivas no trabalho em ciências e em outras disciplinas. Nessa direção, Hartmann e Zimmermann (2009) destacam que são perceptíveis as seguintes mudanças: crescimento pessoal e a ampliação dos conhecimentos; ampliação da capacidade comunicativa; mudanças de hábitos e atitudes; desenvolvimento da criticidade; maior envolvimento e interesse; exercício da criatividade que conduz à apresentação de inovações e maior politização dos participantes. Através da observação das 
atividades da Feira de Ciências verifica-se que essas habilidades são de fato acrescentadas na formação pessoal, social e profissional dos alunos.

Durante a realização da Feira de Ciências da UFG/RC os alunos apresentaram trabalhos e para isto precisaram estudar, pesquisar e interpretar dados sobre o assunto do trabalho de forma a primeiramente entender e assim poder explicar aos visitantes da Feira de Ciências; este processo permitiu que os alunos aprendessem a aprender e ainda desenvolvessem diversas competências e habilidades como criar, pois precisaram elaborar um projeto de forma criativa; apreender de forma diferenciada, pois foram chamados a buscar o conhecimento e não recebê-lo de forma passiva; a falar em público e se comunicar, pois tiveram que mostrar seus trabalhos aos visitantes e serem cidadãos críticos, pois foram instigados a buscar as aplicações e implicações sociais e ambientais de seus projetos.

A fim de se avaliar se os alunos haviam construído competências/habilidades, no questionário aplicado os alunos foram inquiridos sobre o que acreditavam que havia sido acrescentado em suas formações através de sua participação na Feira de Ciências da UFG/RC; ou seja, quais competências/habilidades acreditavam ter adquirido durante a elaboração e o desenvolvimento do trabalho apresentado na Feira. Nas respostas, $100 \%$ dos alunos que responderam ao questionário afirmaram ter construído algum tipo de competência ou habilidade. As competências e habilidades citadas foram as seguintes: trabalhar em grupo; apreender de forma diferenciada; pesquisar informações; analisar e selecionar informações; aprender a criar; ter capacidade de formular seus próprios trabalhos e compreender/conhecer as aplicações dos mesmos no cotidiano; os alunos também relataram que aprenderam a comunicar-se em público.

Assim, quando os dados obtidos nos questionários foram tratados observouse que $57 \%$ dos alunos afirmaram ter adquirido a capacidade de pesquisar informações; acredita-se que isso foi possível pois os alunos foram incentivados a buscar informações de forma autônoma e assim tiveram a oportunidade de serem sujeitos ativos na construção dos seus próprios conhecimentos, pois foram os responsáveis pela pesquisa do projeto e por elaborar e desenvolver seus trabalhos. 
Isso corrobora com uma das mudanças que os autores Mancuso (2000) e Lima (2008) destacam, qual seja, a ampliação dos conhecimentos, pois em uma Feira de Ciências os alunos e professores mobilizam-se para buscar e aprofundar temas científicos que, geralmente, não são debatidos em sala de aula. Há que se acrescentar que aqui neste caso tais temas científicos aparecem de forma contextualizada, de modo que os conteúdos científicos apareceram sempre vinculados a suas aplicações e impactos tecnológicos, sociais e ambientais.

Enquanto isso, 28\% dos alunos afirmaram ter aprendido a analisar e selecionar as informações a partir da elaboração e do desenvolvimento de seus trabalhos para a Feira de Ciências da UFG/RC. Assim, foi alcançado um dos objetivos dos organizadores, pois se notou que os alunos saíram da posição de alunos passivos para alunos críticos/reflexivos. Isso é bastante positivo na formação dos alunos porque é necessária a superação do ensino tradicional, onde os alunos são meros receptores do conhecimento. Ou seja, os alunos tiveram uma mudança de atitude e o desenvolvimento da iniciativa.

Porém, apesar de se acreditar que as Feiras de Ciências sejam uma metodologia que podem promover uma aprendizagem significativa, somente $30 \%$ dos alunos afirmaram ter adquirido a competência/habilidade de aprender de forma diferenciada. Acredita-se que este resultado seja pelo fato dos mesmos não perceberem que apesar desta atividade não ser desenvolvida dentro das salas de aulas é capaz de promover a aprendizagem de uma forma indireta, sem que o aluno perceba. Porém, conforme citado anteriormente, todos os alunos afirmaram que adquiriram competências e habilidades durante o desenvolvimento da Feira, o que até parece ser um paradoxo com esta questão.

Para $18 \%$ dos alunos esta atividade possibilitou a capacidade de formular seus próprios trabalhos e reconhecer as aplicações dos mesmos no cotidiano. Enquanto isso, 39\% afirmaram ter adquirido a capacidade de criar.

Verifica-se que os alunos tiveram um posicionamento crítico e autônomo em relação ao desenvolvimento das suas atividades, pois muitos conseguiram formular e criar projetos dentro de sua área de interesse, possibilitando a estes serem pessoas criativas frente as problemáticas da sociedade. Mais uma vez se averígua a 
capacidade que as Feiras de Ciências têm de melhorar o ensino e formar cidadãos atuantes na sociedade. Conforme Hartman e Zimmermann (2009) trabalhos apresentados em Feiras de Ciências exigem grande mobilização cognitiva e afetiva por parte dos alunos que, orientados por um professor, desenvolvem um trabalho em que exercitam sua capacidade de investigação e de construção de conhecimentos. As leituras, pesquisas, entrevistas, ou a realização de experiências, bem como a necessidade de sistematização e de preparação da apresentação exigem dos alunos um esforço que requer planejamento e, quando realizado em grupo, trabalho em equipe (Mancuso 2000); (Lima 2008).

Segundo a análise dos dados, 35\% dos alunos afirmaram ter experienciado a habilidade/competência de trabalhar em grupo. Quando os mesmos foram questionados por que gostaram de trabalhar em grupo, 32\% afirmaram ter sido "legal", divertido e bom, conforme afirmações como as que seguem:

"É sempre bom trabalharmos em grupos, pois em grupos trocamos ideias e apreendermos a viver socialmente". (A25)

"Encontro de ideias, onde aprendemos [...]" (A6)

Através das falas, percebe-se que este tipo de atividade aproxima os alunos, além de aproximá-los do professor; ou seja, as Feiras de Ciências promovem a interação entre aluno-aluno e professor-alunos. Müller (2002) considera que uma das ferramentas essenciais para o processo de ensino/aprendizagem é a relação professor-aluno; a autora ainda afirma que esta relação possui a capacidade de dinamizar e dá essência no processo de educação. Enquanto isso, Garcia et. al (2006) relata que a partir do contato, ou seja, quando um aluno se relaciona com outro, o processo de ensino/aprendizagem é melhorado.

Para, $2 \%$ dos alunos foi importante trabalhar em grupo, pois esta é uma competência/habilidade importante para sua formação, por possibilitar a cooperação e socialização de informações. Ou seja, com o trabalho em grupo os alunos aprendem a aceitar as ideias e as críticas dos colegas (sociedade). Observou-se um grande entrosamento entre os grupos e alguns chegaram a relatar que é de extrema relevância o desenvolvimento de metodologias que possuam este caráter. Porém, alguns alunos afirmaram não ter gostado de trabalhar em grupo: 
"Foi complicado trabalhar em grupo, pois uns queriam de um jeito outros de outro". (A42)

"É difícil, nem todos os alunos podiam encontrar no horário marcado (A25)."

Mesmo alguns alunos não tendo gostado do trabalho em grupo, acredita-se que esta atividade foi importante em suas formações, pois possibilitou que aprendessem o quanto é importante respeitar as opiniões dos outros, além de tentar resolver os problemas existentes em um grupo. Ou seja, a Feira de Ciências da UFG/RC permitiu que os alunos aprendessem a aceitar críticas e a opinião das outras pessoas, o que é de suma importância para o convívio em sociedade.

Para 36\% dos alunos, a partir da Feira de Ciências da UFG/RC aprenderam a se comunicar em público. Sabe-se que a formação atual não deve basear-se somente em conteúdos, mas sim em conhecimentos/experiências que os alunos levem para a vida. E a comunicação é uma competência de grande importância, tanto para a formação profissional quanto para a pessoal. A ampliação da capacidade comunicativa se dá devido à troca de ideias, ao intercâmbio cultural e ao relacionamento com outras pessoas. Considerando-se que a linguagem é um poderoso instrumento de organização das ideias, elaboração e sistematização de conhecimentos, observa-se que a apresentação de um trabalho em uma Feira de Ciências desenvolve no aluno a capacidade de comunicar e discutir temas de diversas áreas do conhecimento.

No questionário os alunos foram ainda questionados sobre a apresentação de seus projetos e todos (100\%) afirmaram que gostaram de suas apresentações. Porém, somente $36 \%$ afirmaram ter adquirido a competência/habilidade de se comunicar em público. Estes afirmaram que as apresentações permitiram expor suas opiniões, mostrar as etapas dos trabalhos desenvolvidos, além dos pontos positivos e negativos dos mesmos. Relataram ainda o quanto o professor contribuiu para as apresentações em público:

"Consegui expor todas as etapas de desenvolvimento e conclusão do projeto, enfatizando os objetivos alcançados." (A22), 
"[...] gostei, porque conseguimos expor de forma clara e concisa o nosso trabalho." (A35)

Devido ao fato dos alunos terem que apresentar seus trabalhos, os mesmos tiveram que buscar o embasamento teórico para tal, além de terem que estudar as aplicações dos trabalhos no cotidiano. Isso é interessante, pois se percebe mais uma vez que os alunos foram incentivados a se tornarem sujeitos ativos na construção de seus conhecimentos, foram estimulados à pesquisa e a serem autônomos.

Assim, pela análise dos dados obtidos, percebe-se que a Feira de Ciências da UFG/RC configurou-se em um acréscimo positivo na formação dos alunos ao possibilitar o desenvolvimento de diversas competências e habilidades previstas na Legislação Educacional, como por exemplo nos PCN's (Parâmetros Curriculares Nacionais para o Ensino Médio) (BRASII,1999). Como os alunos foram retirados da posição passiva/receptora do ensino tradicional, de meros expectadores foram incentivados para a autonomia, para a busca pelo conhecimento. Isto possibilitou que se tornassem sujeitos ativos na construção de conhecimentos científicos, tecnológicos, sociais, morais e ambientais, conhecimentos estes que são essenciais para atuarem na sociedade de forma crítica e reflexiva, tendo assim uma visão ampla do mundo em que vivem. Então, após constatar o desenvolvimento de diversas competências e habilidades, percebe-se que a Feira de Ciências da UFG/RC se constituiu em uma ótima metodologia que vem de encontro às necessidades discutidas na atual legislação educacional brasileira de promoção de competências e habilidades para a formação cidadã dos alunos.

\section{Feira de Ciências e Formação Cidadã}

Um dos propósitos da Feira de Ciências da UFG/RC é o de promover uma formação cidadã consciente. Porém, somente $24 \%$ dos alunos admitiram que a Feira de Ciências de UFG/RC Ihes proporcionou a almejada formação cidadã. Isso mais uma vez evidencia que nem sempre os alunos percebem que atividades desta natureza, fora de uma sala de aula, podem possibilitar uma formação de qualidade, 
voltada para um crescimento pessoal, profissional e social. Porém, todos os dados obtidos se contrapõem a esta afirmação dos alunos, como pode ser verificado nas análises a seguir.

Desta forma, umas das sondagens realizadas pelas autoras foi no sentido de verificar qual a visão dos discentes envolvidos nas atividades da Feira de Ciências da UFG/RC para a formação cidadã e a importância desta metodologia, para seu crescimento cognitivo, social, ambiental e ético. Neste contexto os alunos foram inquiridos sobre qual sua visão da Feira de Ciências da UFG/RC para sua formação.

Para 25\% dos alunos este tipo de atividade é de suma importância devido ao fato de que durante o desenvolvimento dos trabalhos os participantes são estimulados a pensar, tomar posicionamentos, além de outras:

"Conhecer e explorar a capacidade de cada um, pois é possível se criar um mundo de maior responsabilidade." (A30)

Vale destacar que um dos objetivos primordiais da formação cidadã é que os indivíduos não sejam responsáveis e preocupados simplesmente consigo mesmos, mas que se preocupem também com a sociedade como um todo, numa atitude solidária e benevolente. O que se nota durante as Feiras de Ciências da UFG/RC é que os participantes demostram possuir uma responsabilidade individual e social, ou seja, uma responsabilidade pelo mundo em que vivem. Alguns trabalhos de destaque (apontados pelos visitantes) foram aqueles que possuíam um caráter de conscientização e demostravam a responsabilidade pela sociedade em que vivemos, podendo se citar o impacto da extração mineral em Catalão-GO, onde os responsáveis pelo trabalho discutiram tanto os benefícios quanto os malefícios da mineração para a região. Um outro trabalho de destaque foi o reaproveitamento de resíduos sólidos recicláveis para a criação de uma Oficina de Matemática; neste trabalho os autores discutiram a minimização do consumo e o quanto é importante a reciclagem e a reutilização de materiais. Outro trabalho de grande repercussão foi "Aids, nem os super-heróis estão livres"; neste os autores abordaram/retrataram algumas doenças sexualmente transmissíveis e discutiram como preveni-las. Notouse que os alunos responsáveis pelos trabalhos realmente se engajaram com a 
problemática do tema abordado, buscando informações sobre a temática e levantando dados para a apresentação desta. Por exemplo, pode-se citar o último trabalho, onde os integrantes do grupo relataram que foram em postos de saúde saber sobre o histórico da Aids na cidade de Catalão e sobre outras doenças sexualmente transmissíveis; estes fizeram ainda a distribuição de preservativos masculinos e femininos durante o evento para os visitantes que prestigiaram seu trabalho. Assim, observa-se que o desenvolvimento de trabalhos em Feiras de Ciências permite aos alunos serem mais responsáveis, pois a atividade permite refletir mais sobre a sua realidade e os problemas da sociedade, o que consequentemente contribui efetivamente para a formação cidadã dos alunos.

Averígua-se ainda através das falas e da observação das atividades que o contato com outras pessoas dentro do ambiente da Feira de Ciências da UFG/RC oportuniza aos participantes o acréscimo de valores culturais e sociais, formação esta prevista na Legislação Educacional Brasileira como os PCNs (BRASIL 1999a). As atividades da Feira permitiram que os alunos conhecessem pessoas diferentes e trabalhos novos, permitindo a interação e a socialização com o novo. Como a atividade contou com a participação de alunos tanto do nível fundamental como do ensino médio, sendo estes ainda provenientes de duas realidades distintas, pública e privada e também de escolas de nível técnico e ainda com a visita de alunos da universidade houve a interação de culturas diferentes, um ponto que muitas vezes não é comum aos alunos dentro de uma sala de aula. Isto proporciona um crescimento cultural, importante na formação cidadã dos alunos e que na maioria das vezes não é possível de ser feito dentro das escolas. Sendo assim, a Feira de Ciências da UFG/RC contribui para o desenvolvimento social dos alunos, ponto muito importante, como também para o desenvolvimento do respeito mútuo e a compreensão das diferenças.

Vinte e um por cento (21\%) dos alunos ainda afirmaram que a Feira de Ciências da UFG/RC possibilitou aprender sobre meio ambiente, como: sustentabilidade, ser um cidadão sustentável e sobre tecnologia. Vale destacar que uma das justificativas dos alunos terem essa visão de educação ambiental é que no regulamento para exposição de trabalhos da Feira de Ciências da UFG/RC se 
incentiva que os alunos trabalhem com materiais mais sustentáveis e viáveis para o meio ambiente. Assim, houve trabalhos apresentados na Feira com abordagens e temáticas ambientais. Caverdon et. al. (2006) declara a importância da Educação Ambiental na formação cidadã dos alunos, estando a mesma prevista na Lei 9795/99, na Política Nacional de Educação Ambiental (PNEA) (BRASIL, 1999b), que em seu artigo $1^{\underline{a}}$ afirma que a Educação Ambiental é um dos meios pelo qual o sujeito tem a possibilidade de construção de valores sociais, conhecimentos, habilidades, atitudes e competências voltadas para uma sociedade sustentável. Destaca-se que a Educação Ambiental faz parte do processo educativo e é um componente essencial para a formação cidadã.

Assim, através das análises das respostas dos alunos percebe-se o quanto são importantes atividades como a Feira de Ciências de UFG/RC na formação dos alunos, que esta realmente é capaz de promover a formação cidadã prevista na legislação educacional, pois estas possibilitam um acréscimo significativo na formação dos alunos como pôde ser observados pelos resultados obtidos.

\section{Feiras de Ciências: Aproximando Universidade e Escola Básica}

Nos questionários os alunos foram inquiridos se esta era a primeira visita que faziam a UFG/RC; $82 \%$ dos alunos disseram que sim, enquanto $18 \%$ afirmaram que já conheciam o Campus de outras oportunidades, como de outras Feiras de Ciências da UFG/RC e Feiras de Profissões.

Quando questionados se achavam importante realizarem visitas à Universidade, todos os alunos afirmaram que $\operatorname{sim}(100 \%)$. Quando foram solicitados a justificar, $41 \%$ afirmaram que as visitas podem contribuir para a formação dos alunos e ainda justificaram que é uma oportunidade de conhecer o seu futuro ambiente de estudos, pois pretendem ingressar na Universidade: "É importante, já que daqui há tempos iremos estudar aqui e é bom que já vamos conhecendo." (A11)

Já $12 \%$ dos alunos relataram que este tipo de atividade é importante, pois possibilita que os alunos da educação básica conheçam o trabalho que as Universidades desenvolvem. Isso é interessante, pois muitas vezes a Universidade 
fica distante da sociedade, como se fosse um mundo à parte. Portanto, atividades como estas podem promover uma aproximação da Universidade com a escola básica e a comunidade; o que se verifica é que as vezes a acadêmica fica distante da escola, um fato ruim, pois esta aproximação traz pontos positivos para ambos. $O$ restante (47\%) dos alunos, disseram que é importante devido ao fato das Feiras de Ciências serem atividades que possibilitam o acúmulo de experiências, ou seja, de ensinar e apreender sobre a vida, de conhecer mais sobre a educação, a oportunidade de apreender, de construir o raciocínio e também de desenvolver raciocínio lógico.

Portanto, acredita-se que as Feiras de Ciências são ótimas metodologias de ensino, que podem ser utilizadas na Educação Básica, pois estas vem de encontro aos objetivos expressos na Legislação Educacional Brasileira, quais sejam o de uma formação cidadã, baseada no desenvolvimento da autonomia intelectual, na formação ética e no pensamento crítico.

\section{CONCLUSÕES}

Acredita-se que para que haja a efetivação de um processo de ensino e aprendizagem que objetive a formação de cidadãos críticos e reflexivos e que tenham uma visão ampla de mundo é necessário que se proporcione a estes alunos a vivência de metodologias que venham de encontro às necessidades dos mesmos e que superem o ensino conteudista ainda encontrado nas escolas de hoje. Após análises, acredita-se que as Feiras de Ciências da Universidade Federal de Goias/Regional Catalão (UFG/RC) cumprem esse papel.

Ficou evidente que as Feiras de Ciências da UFG/RC promoveu na vida e na formação dos alunos uma série de habilidades e competências, como relatadas por estes, dando a estes: capacidade de criar, pesquisar, buscar e selecionar informações, capacidade de trabalhar em grupo, de se comunicar em público, de ter a capacidade de pensamento crítico frente às questões de cunho social e ambiental, possibilitando que os mesmos adquirissem a capacidade de julgar os problemas cotidianos e de ter uma visão ampla do mundo em que vivem, além de promover na 
vida destes a reflexão sobre os problemas ambientais que a sociedade está vivenciando.

Foi evidenciado o quanto metodologias neste âmbito são importantes, pois a partir delas há aproximação entre a escola e comunidade escolar que hoje se encontra muito distante da escola.

\section{REFERÊNCIAS BIBLIOGRÁFICAS}

BARCELOS, N. N. S., JACOBUCCI, G. B., JACOBUCCI, D. F. C. Quando o cotidiano pede espaço na escola, o projeto da feira de ciências "vida em sociedade" se concretiza. Ciência \& Educação, Bauru, v. 16, n. 1, p. 215-233, 2010.

BRASIL, Ministério da Educação e do Desporto. Secretaria de Educação Fundamental. Parâmetros Curriculares Nacionais: Química. MEC/SEF, 1999a.

BRASIL. Ministério do Meio Ambiente. Lei n9.795, de 27 de abril de 1999. Dispõe sobre a educação ambiental, institui a Política Nacional de Educação Ambiental e dá outras providências. Brasília, 1999b.

BRASIL. Lei de Diretrizes e Bases da Educação: Lei no 9.394/96 - 24 de dez. 1996. Estabelece as diretrizes e bases da educação nacional. Brasília, 1996.

CAVERDON, C. C., RUCKER, A., KRAY, J.G. Gincana Ambiental: o despertar da consciência ecológica. Educação ambiental, vários olhares e várias práticas. Porto Alegre: Editora Mediação, 2006.

GARCIA, E. O., PANVANI, A. A., LIMONGE, P. S. M., COSTA. E. E. M. Estudo da relação professor/aluno e aluno/aluno. In: Anais do 14를 Simpósio Internacional de Iniciação Científica da USP (SIICUSP), São Paulo-SP, 2006. Disponível em: $<$ https://uspdigital.usp.br/siicusp/cdOnlineTrabalhoVisualizarResumo?numerolnscric aoTrabalho=1027\&numeroEdicao=14>. Acesso em: 2 dev. 2016.

HARTMANN, M, A., ZIMMERMANN, E. Feira de Ciências: Interdisciplinaridade e a contextualização em produções de estudantes do Ensino Médio. Florianópolis, Anais do: VIII Encontro Nacional de Pesquisa em Educação em Ciências (ENPEC.) pg. 12, 2009.

LIMA, M. E. C. Feiras de ciências: o prazer de produzir e comunicar. In: PAVÃO, A. C.; FREITAS, D. Quanta ciência há no ensino de ciências. São Carlos: EduFSCar, 2008. 
LIMA, M. C. Feiras de ciências: a produção escolar veiculada e o desejo de conhecer o aluno. Recife: Espaço Ciência, 2004.

MANCUSO, R. Feiras de ciências: produção estudantil, avaliação, consequências. Contexto Educativo. Revista digital de Educación y Nuevas Tecnologias, n. 6, abr. 2000. Disponível em: < http://contexto-educativo.com.ar/2000/4/nota-7.htm> Acesso em: 23 out. 2015.

MANCUSO, R. Programa estadual de Feiras de Ciências do Rio Grande do Sul. Porto Alegre: SEC/CECIRS, 1995.

MORAES, R. Analise Textual Discursiva: Processo Reconstrutivo de Múltiplas faces. Ciências e Educação, v. 12, n. 1, p. 171-128, 2003.

MORAES, R.; GALIAZZI, M. C. Análise textual discursiva. ljuí: Unijui, 2007.

MORIN, E. Os Setes Saberes Necessários à Educação do Futuro. São Paulo. Cortez; Brasília, DF: UNESCO, 2007.

MÜLLER, L. S. A interação professor-aluno no processo educativo. Integração, São Paulo, ano VIII, n. 31, p. 276-280, nov. 2002. Disponível em: < http:// www.usjt.br/prppg/revista/integracao_31.php > Acesso em: 2 fev. 2016.

PAVÃO A.C. Feiras de Ciências: revolução pedagógica. Recife: Espaço Ciência. 2004. Disponível em: <http://www.espacociencia.pe.gov.br/artigos/?artigo=6>. Acesso em: 30 out. 2015.

PEREIRA, A. B., OAIGEN, E. R., HENNING, G. J. Feiras de ciências. Canoas: ULBRA, 2000. 